\title{
cPKC $\gamma$ membrane translocation is involved in herkinorin-induced neuroprotection against cerebral ischemia/reperfusion injury in mice
}

\author{
XIAOCHEN GUI $^{1,2}$, XU CUI $^{1}$, HAIPING WEI ${ }^{3}$, GUANG FENG $^{1}$, \\ XUEZHENG ZHANG ${ }^{1}$, YONGJIN HE ${ }^{2}$, JUNFA $\mathrm{LI}^{3}$ and TIANZUO LI ${ }^{1,4}$ \\ ${ }^{1}$ Department of Anesthesiology, Beijing Tongren Hospital, Capital Medical University, Beijing 100730; \\ ${ }^{2}$ Department of Anesthesiology, Tianjin Hospital, Tianjin 300211; ${ }^{3}$ Department of Neurobiology, \\ Beijing Institute for Brain Disorders, Capital Medical University, Beijing 100069; ${ }^{4}$ Department of Anesthesiology, \\ Beijing Shijitan Hospital, Capital Medical University, Beijing 100038, P.R. China
}

Received October 20,2015; Accepted November 1, 2016

DOI: $10.3892 / \mathrm{mmr} .2016 .5995$

\begin{abstract}
Herkinorin is an opiate analgesic with limited adverse effects, functioning as a primary selective atypical opioid $\mu$ agonist. The present study aimed to identify whether herkinorin has a positive effect on ischemic/reperfusion (I/R) injury. Adult male C57BL/6 mice were randomly divided into five groups: i) Naïve, ii) sham, iii) $I / R$, iv) $I / R$ with dimethyl sulfoxide $(\mathrm{I} / \mathrm{R}+\mathrm{D})$ and $\mathrm{v}) \mathrm{I} / \mathrm{R}$ with herkinorin $(\mathrm{I} / \mathrm{R}+\mathrm{H})$. The $\mathrm{I} / \mathrm{R}$ injury model was induced by occluding the middle cerebral artery for $1 \mathrm{~h}$ followed by $24 \mathrm{~h}$ or 7 days of reperfusion. Neurobehavioral scores and sensorimotor functions were examined $24 \mathrm{~h}$ and 7 days following reperfusion. In addition, infarct volumes were examined at these time points using a 2,3,5-triphenyltetrazolium chloride assay. Herkinorin treatment improved neurobehavioral and sensorimotor functional recovery from $\mathrm{I} / \mathrm{R}$-induced brain injury. There was a significant decrease in infarct volume in the $\mathrm{I} / \mathrm{R}+\mathrm{H}$ group at $24 \mathrm{~h}$ or 7 days following reperfusion compared with the I/R and I/R+D groups. Western blotting suggested that the decrease in conventional protein kinase $\mathrm{C} \gamma(\mathrm{cPKC} \gamma)$ membrane translocation in the peri-infarct region may be attenuated by herkinorin pretreatment. These results indicated that herkinorin may be beneficial in I/R-induced mouse brain injury, and this may be attributed to the membrane translocation of $\mathrm{CPKC} \gamma$ following activation.
\end{abstract}

\section{Introduction}

Due to an aging population, stroke has become the second leading cause of mortality and adult disability in China.

Correspondence to: Dr Tianzuo Li, Department of Anesthesiology, Beijing Tongren Hospital, Capital Medical University, 2 Chongwenmennei Street, Dongcheng, Beijing 100730, P.R. China E-mail: sjtmzltz@163.com

Key words: herkinorin, neuroprotection, protein kinase $\mathrm{C}$, membrane translocation, ischemia/reperfusion
Stroke-associated neurological deficits exert a negative effect on the language, cognition and motor function of patients. In addition, stroke places a heavy emotional burden on caregivers and a financial burden on health systems. The only Food and Drug Administration-approved therapeutic agent for the treatment of ischemic stroke, recombinant tissue plasminogen activator, is suitable for use only within a narrow time window; as a result only $2 \%$ of stroke patients benefit from this therapy. Therefore, the development of novel agents for the treatment of stroke is required.

Opioids have been demonstrated to alleviate ischemia/reperfusion (I/R) injury in a number of organs when administered prior to ischemia or at the time of reperfusion (1-3). In addition, certain studies have demonstrated that opioids may be involved in protecting neurons from hypoxic and ischemic stress in vivo and in vitro (4-6). However, the risk of adverse effects, including respiratory depression, constipation, and physical and psychological dependence, has made physicians wary of prescribing these drugs.

Salvinorin A (SA) is a natural hallucinogen from which herkinorin, the first $\mu$ opioid selective agonist, is derived. Herkinorin does not promote the recruitment of $\beta$-arrestin- 2 to the $\mu$-opioid peptide (MOP) receptor, a quality exhibited by the majority of other opioids, and does not lead to receptor internalization (7). As certain studies in mice have revealed that the interaction between $\beta$-arrestin- 2 and the opioid receptor is important in the development of opioid-induced tolerance, constipation and respiratory depression, herkinorin may provide therapeutic benefits with limited adverse effects $(8,9)$. It has been demonstrated that opioid agonists have a protective effect against ischemic injury (1-3). A study conducted by Chen et al (10) revealed that administration of SA improved neurological function and reduced the mortality rate following hypoxic injury. The present study hypothesized that herkinorin may have similar positive effects on I/R injury.

Transient middle cerebral artery occlusion (MCAO) in mice was used to mimic human stroke. Neurobehavioral scores and sensorimotor functions were examined $24 \mathrm{~h}$ and 7 days following induction of MCAO. Infarct volumes were 
examined at these time points using the 2,3,5-triphenyltetrazolium chloride (TTC) assay.

Conventional protein kinase $\mathrm{C} \gamma(\mathrm{cPKC} \gamma)$ is a member of the classical PKC subfamily, and its localization is restricted to brain and spinal cord neurons. It is an important component of the signal transduction pathways involved in neuroprotection. Previous studies have demonstrated that ischemic injury protection is associated with an increase in the membrane translocation of cPKC $\gamma$, from the cytosol to the particulate fraction $(11,12)$. Therefore, cell fraction and western blot analysis were used to investigate whether the subcellular localization of $\mathrm{cPKC} \gamma$ is involved in the protective effects of herkinorin pretreatment against cerebral I/R injury.

\section{Materials and methods}

Animals. A total of 60 adult male C57BL/6 mice (age, 12-14 weeks; weight, 18-22 g) were purchased from Beijing Vital River Laboratory Animal Technology Co., Ltd. (Beijing, China). The mice were housed under conventional conditions (temperature, $21 \pm 1^{\circ} \mathrm{C}$, relative humidity $60 \pm 10 \%$,) under a $12 \mathrm{~h}$ light/dark cycle and were allowed free access to food and water. Animals were randomly divided into five groups: i) Naïve, ii) sham, iii) I/R, iv) I/R with dimethyl sulfoxide (DMSO; I/R+D) and v) I/R with herkinorin $(\mathrm{I} / \mathrm{R}+\mathrm{H})$. The experimental procedures were carried out in accordance with the Animal Protection Law of the People's Republic of China and were approved by the animal ethics committee of Beijing Tongren Hospital affiliated to the Capital Medical University.

Animal model. The MCAO model of permanent focal cerebral ischemia was conducted as previously reported (13). Following anesthesia with an intraperitoneal injection of $0.06 \mathrm{~g} / \mathrm{kg}$ pentobarbital sodium (Ovation Pharmaceuticals, Inc., Deerfield, IL, USA), the left common carotid artery and ipsilateral external carotid artery were exposed and ligated via a ventral midline neck incision. An arteriotomy in the common carotid artery was made, allowing the introduction of a blunt-tipped 4-0 surgical monofilament (0.23-mm diameter; Guangzhou Jialing Biotechnology Co., Ltd., Guangzhou, China) to a point $\sim 12 \mathrm{~mm}$ distal to the carotid bifurcation until a mild resistance was felt, thereby occluding the origin of middle cerebral artery. The nylon thread was removed to allow reperfusion $1 \mathrm{~h}$ following occlusion. In the sham group, the mice underwent surgical exposure of carotid artery and ligation without insertion of an intraluminal filament. Body temperature was maintained throughout the surgery with a heating lamp and thermal blanket. Mice were placed in a post-operative cage, and kept warm and undisturbed for a minimum of $2 \mathrm{~h}$ for observation.

Drug administration. Mice in the $\mathrm{I} / \mathrm{R}+\mathrm{H}$ group were treated with $10 \mathrm{mg} / \mathrm{kg}$ herkinorin (Abcam, Cambridge, UK) dissolved in $10 \%$ DMSO via intraperitoneal injection $3 \mathrm{~h}$ prior to cerebral ischemia induction. In the $\mathrm{I} / \mathrm{R}+\mathrm{D}$ group, an equal volume of DMSO was administered.

Neurobehavioral analyses. To investigate whether herkinorin promotes neurologic recovery following I/R, an array of neurobehavioral analyses were performed at $24 \mathrm{~h}$ and 7 days following reperfusion by an investigator who was blinded to the experimental groups.

Neurological scoring. Neurological scoring was based on that reported by Rodriguez et al (14) and was as follows: 0, no neurological dysfunction; 2, slight decrease in mobility and the presence of passivity; 4 , moderate neurological dysfunction and additional alterations, including moderate hypomobility, flattened posture, lateralized posture, hunched back, ataxic gait, decreased body tone and muscular strength, and slight motor incoordination; 6 , disabled but able to walk, with more marked hypomobility, circling, tremor, jerks and/or convulsions, forelimb flexion, and moderate motor incoordination; 8 , respiratory distress, total incapacity to move/coordinate; 10 , death. If the criteria for a precise grade given in the scoring list were not met, the nearest appropriate number was utilized: $1,3,5,7$ or. 9 .

Pole test. The pole test was performed as described by Matsuura et al (15), with minor modifications. The test apparatus consisted of a vertical steel pole covered with tape, which acted to create a rough surface. The mice were placed head upward on the top of the pole. The 'time turn' was recorded, which was defined as the time taken by the mouse to turn completely head downward. In addition, the 'time total' was recorded, defined as the time it took the mouse to descend down the pole and reach the floor with its front paws. If the animal was unable to turn completely, the time taken to reach the floor was also attributed to the time total.

Wire hang test. This test was used to measure neuromuscular strength as previously described (16). Mice were placed gently on a wire mesh and the hanging time until the mice fell onto the soft bedding below was recorded, with a cut-off time of $300 \mathrm{sec}$.

Cylinder test. Mice were placed in a clear plexiglass cylinder $(30 \times 20 \mathrm{~cm})$ as previously described (17). Left or right paw vertical exploration movement was scored for each contact with the glass wall. Simultaneous contact by the two paws was scored separately. A total of 20 contacts were recorded for each mouse. The laterality index was calculated as follows: [Contacts (left)-contacts (right)]/[contacts (left)+contacts (right)+contacts (both)].

Foot-fault test. This test aimed to measure the accuracy of forepaw placement on non-equidistant grids, as previously described (18). The total number of steps that the mouse used to cross the grid was counted, and the total number of foot-faults for the left forelimb was recorded. The results were presented as the percentage of the foot-fault measurement of the left paw, of the total number of steps.

Measurement of infarct size. Mice were sacrificed at $24 \mathrm{~h}$ or 7 days following reperfusion, and the brain was rapidly removed and cut into 1.5-mm thick coronal sections (five sections from each brain). The slices were incubated in a solution of $0.5 \%$ TTC (Sigma-Aldrich; Merck Millipore, Darmstadt, Germany) dissolved in $10 \mathrm{mM}$ phosphate-buffered saline at $37^{\circ} \mathrm{C}$ for 
$20 \mathrm{~min}$, and subsequently imaged. The images of stained slices were scanned into a computer and the infarct volume was determined using Image-Pro ${ }^{\circledR}$ Plus software version 6.0 (Media Cybernetics Inc., Rockville, MD, USA), as reported by Wexler et al (19).

Sample preparation and western blot analysis. Following completion of behavioral testing at $24 \mathrm{~h}$ after reperfusion, animals were deeply anesthetized and decapitated. Brains were removed and placed into ice-cold $\left(4^{\circ} \mathrm{C}\right)$ artificial cerebral spinal fluid (ACSF: $125.0 \mathrm{mM} \mathrm{NaCl}, 2.5 \mathrm{mM} \mathrm{KCl}, 2.0 \mathrm{mM}$ $\mathrm{CaCl}_{2}, 26.0 \mathrm{mM} \mathrm{NaHCO} 3,1.25 \mathrm{mM} \mathrm{NaH} \mathrm{PO}_{4}, 1.0 \mathrm{mM}$ $\mathrm{MgCl}_{2}, 10.0 \mathrm{mM}$ glucose, $\mathrm{pH}$ 7.4). Regions from left hemispheres that corresponded to the ischemic core, peri-infarct region and contralateral non-ischemic region were dissected, in accordance with a previous study (20). Briefly, the left-brain was sectioned (four slices; 2-mm thick) and the tissue supplied by the anterior cerebral artery was removed through a longitudinal cut (from top to bottom) $\sim 2 \mathrm{~mm}$ from the midline. The ischemic core and peri-infarct region were separated by a transverse diagonal cut at approximately the ' 2 o'clock' position. A contralateral control consisted of the corresponding regions from the non-ischemic hemisphere. Samples were frozen in liquid nitrogen and kept at $-80^{\circ} \mathrm{C}$ until analysis.

Cytosolic and particulate proteins were extracted as described in a previous study (21). In brief, frozen slices were thawed and homogenized at $-4^{\circ} \mathrm{C}$ in buffer A $[50 \mathrm{mM}$ Tris-Cl, pH 7.5, containing $2 \mathrm{mM}$ EDTA, $1 \mathrm{mM}$ ethylene glycol-bis ( $\beta$-aminoethyl ether)-N,N,N',N'-tetraacetic acid, $100 \mathrm{mM}$ iodoacetamide (SH-group blocker), $5 \mathrm{~g} / \mathrm{ml}$ each of leupeptin, aprotinin, pepstatin $\mathrm{A}$ and chymostatin, $50 \mathrm{mM}$ potassium fluoride, $50 \mathrm{nM}$ okadaic acid and $5 \mathrm{mM}$ sodium pyrophosphate]. Centrifugation of the homogenates was performed at $30,000 \times \mathrm{g}$ for $30 \mathrm{~min}$ at $4^{\circ} \mathrm{C}$ to yield cytosolic fractions. The pellets were then subsequently resuspended in buffer B (buffer A containing $0.5 \%$ Nonidet P-40) prior to sonication and centrifugation $\left(5,000 \times \mathrm{g}, 30 \mathrm{~min}, 4^{\circ} \mathrm{C}\right)$. The resulting supernatants were particulate fractions. Protein concentrations were determined using a Bicinchoninic Acid kit (Pierce; Thermo Fisher Scientific, Inc., Waltham, MA, USA); albumin diluted in buffer A or B served as a standard.

A total of $40 \mu \mathrm{g}$ protein from each sample was loaded onto $10 \%$ SDS-PAGE gels. Proteins were electrophoresed and transferred onto polyvinylidene difluoride membranes (GE Healthcare Life Sciences, Chalfont, UK) at $4^{\circ} \mathrm{C}$. Following rinsing with TBS containing Tween-20 (20 mM Tris- $\mathrm{Cl}$, $\mathrm{pH} 7.5,0.15 \mathrm{M} \mathrm{NaCl}$ and $0.05 \%$ Tween-20), membranes were blocked with $10 \%$ non-fat milk for $1 \mathrm{~h}$ at room temperature. Membranes were subsequently incubated with the primary antibodies rabbit anti-cPKC $\gamma(1: 1,000$; catalogue number SC-98952; Santa Cruz Biotechnology, Inc., Dallas, TX, USA), and mouse anti- $\beta$-actin (1:1,000; catalogue number A5441 Sigma-Aldrich; Merck Millipore) for $3 \mathrm{~h}$ at room temperature. Membranes were then incubated with the horseradish peroxidase-conjugated goat anti-rabbit or anti-mouse immunoglobulin G secondary antibodies (1:5,000; catalogue numbers ADI-SAB-300-J and ADI-sab-100-J, respectively; Stressgen Biotechnologies Corporation Victoria, BC, Canada) for $1 \mathrm{~h}$ at room temperature. Following incubation with secondary antibodies, an Enhanced Chemiluminescence kit
(GE Healthcare Life Sciences) was used to detect protein bands, which were quantified with the TINA 2.0 densitometry software (Raytest GmbH, Straubenhardt, Germany) and normalized to $\beta$-actin.

Statistical analysis. Data was analyzed using SPSS software version 13.0 (SPSS, Inc., Chicago, IL, USA). All data are presented as the mean \pm standard error. Statistical analysis was performed by one-way analysis of variance followed by all pairwise multiple comparison procedures using the Bonferroni test. $\mathrm{P}<0.05$ was considered to indicate a statistically significant difference.

\section{Results}

Herkinorin treatment improves neurobehavioral and sensorimotor functional recovery from I/R-induced brain injury. Mice in the sham and naïve groups had a neurological score of 0 at $24 \mathrm{~h}$ and 7 days. Following MCAO, there was a significant increase in the neurological function scores in the $\mathrm{I} / \mathrm{R}$ and $\mathrm{I} / \mathrm{R}+\mathrm{D}$ groups $(\mathrm{P}<0.001 \mathrm{I} / \mathrm{R}$ and $\mathrm{I} / \mathrm{R}+\mathrm{D}$ group vs. naïve and sham groups at $24 \mathrm{~h}$ and 7 days) However, the herkinorin treatment group demonstrated a significant improvement in neurological deficit at the two time points (Fig. 1A, $\mathrm{P}=0.006$ and $0.008, \mathrm{I} / \mathrm{R}$ and $\mathrm{I} / \mathrm{R}+\mathrm{D}$ group vs. $\mathrm{I} / \mathrm{R}+\mathrm{H}$ group at $24 \mathrm{~h}$; $\mathrm{P}=0.006$ and $0.009, \mathrm{I} / \mathrm{R}$ and $\mathrm{I} / \mathrm{R}+\mathrm{D}$ group vs. $\mathrm{I} / \mathrm{R}+\mathrm{H}$ group at 7 days).

In the pole test, mice from the $\mathrm{I} / \mathrm{R}$ and $\mathrm{I} / \mathrm{R}+\mathrm{D}$ groups performed worse compared with those in the sham and naïve groups at $24 \mathrm{~h}$ and 7 days. There was a significant decrease of 'time turn' and 'time total' in the $\mathrm{I} / \mathrm{R}+\mathrm{H}$ group compared with the $I / R$ and $I / R+D$ groups at the two time points (Fig. 1B, Time turn: $\mathrm{P}=0.006$ and $0.008, \mathrm{I} / \mathrm{R}$ and $\mathrm{I} / \mathrm{R}+\mathrm{D}$ group vs. $\mathrm{I} / \mathrm{R}+\mathrm{H}$ group at $24 \mathrm{~h} ; \mathrm{P}=0.007$ and $0.008, \mathrm{I} / \mathrm{R}$ and $\mathrm{I} / \mathrm{R}+\mathrm{D}$ group vs. $\mathrm{I} / \mathrm{R}+\mathrm{H}$ group at 7 days. Time total: $\mathrm{P}=0.005$ and $0.007, \mathrm{I} / \mathrm{R}$ and $\mathrm{I} / \mathrm{R}+\mathrm{D}$ group vs. I/R+H group at $24 \mathrm{~h} ; \mathrm{P}=0.005$ and $0.008, \mathrm{I} / \mathrm{R}$ and $\mathrm{I} / \mathrm{R}+\mathrm{D}$ group vs. I/R+H group at 7 days.).

The wire hanging test revealed a significant decrease of latency to fall in the $\mathrm{I} / \mathrm{R}$ and $\mathrm{I} / \mathrm{R}+\mathrm{D}$ groups. However, there was no statistical difference between the herkinorin-treated and non-treated groups (Fig. 1C).

In the cylinder test, the mice in the $\mathrm{I} / \mathrm{R}$ and $\mathrm{I} / \mathrm{R}+\mathrm{D}$ groups demonstrated significant asymmetrical forelimb use for wall exploration. By contrast, sham and naïve animals used left and right paws equally. The forelimb impairment of the contralateral paw to the lesion site was significantly decreased in animals of $\mathrm{I} / \mathrm{R}+\mathrm{H}$ group compared with those of the $\mathrm{I} / \mathrm{R}$ and $\mathrm{I} / \mathrm{R}+\mathrm{D}$ groups at $24 \mathrm{~h}$ and 7 days (Fig. 1D, $\mathrm{P}=0.004$ and 0.006 , $\mathrm{I} / \mathrm{R}$ and $\mathrm{I} / \mathrm{R}+\mathrm{D}$ group vs. $\mathrm{I} / \mathrm{R}+\mathrm{H}$ group at $24 \mathrm{~h} ; \mathrm{P}=0.005$ and $0.008, \mathrm{I} / \mathrm{R}$ and $\mathrm{I} / \mathrm{R}+\mathrm{D}$ group vs. I/R+H group at 7 days).

In the foot fault test, the $\mathrm{I} / \mathrm{R}$ and $\mathrm{I} / \mathrm{R}+\mathrm{D}$ groups demonstrated a significant asymmetric impairment in muscle strength and motor coordination in the limbs of the left side. The herkinorin treatment group revealed a significant improvement of motor deficit at the two time points (Fig. $1 \mathrm{E}, \mathrm{P}=0.005$ and $0.008, \mathrm{I} / \mathrm{R}$ and $\mathrm{I} / \mathrm{R}+\mathrm{D}$ group vs. I/R+H group at $24 \mathrm{~h} ; \mathrm{P}=0.006$ and 0.009 , $\mathrm{I} / \mathrm{R}$ and $\mathrm{I} / \mathrm{R}+\mathrm{D}$ group vs. $\mathrm{I} / \mathrm{R}+\mathrm{H}$ group at 7 days).

Herkinorin reduces infarction volume. The images of cerebral infarction in the various groups are presented in Fig. 2, with 
A

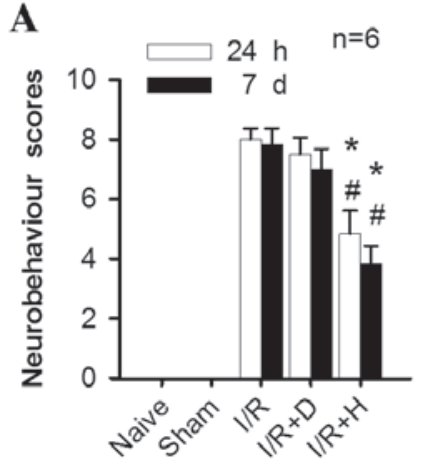

C

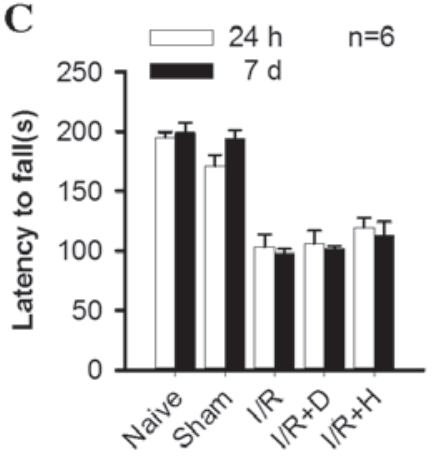

B

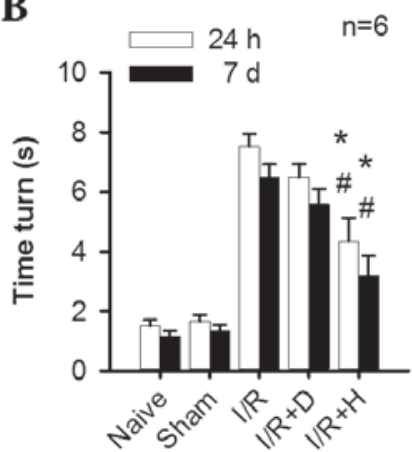

D

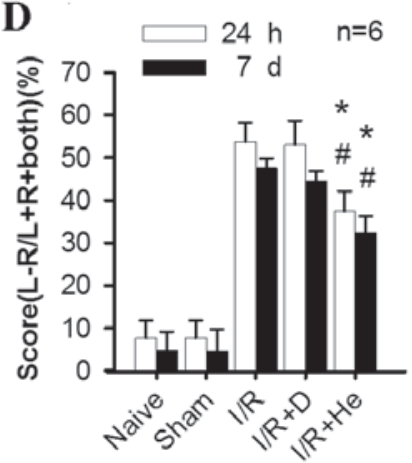

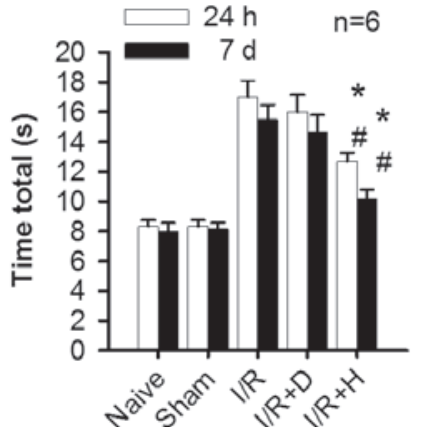

$\mathbf{E}$

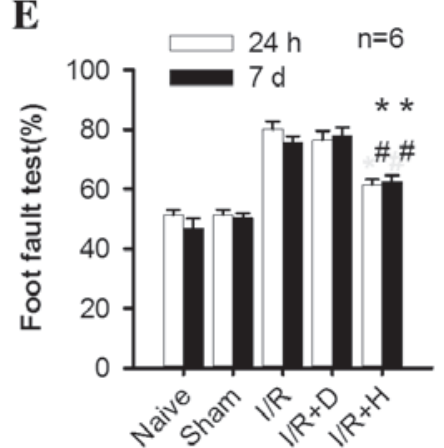

Figure 1. Herkinorin promotes neurobehavioral and sensorimotor functional recovery from I/R induced brain injury. The following assessments were measured at $24 \mathrm{~h}$ and 7 days following reperfusion: (A) Neurological score, (B) time turn and time total, (C) latency to fall, (D) score (L-R/L+R+both) and (E) foot-fault test. Following I/R, mice performed worse in all these tests compared with the naïve and sham groups; herkinorin treatment significantly attenuated this effect, except in the wire hang test, where there was no significant improvement. Data are expressed as the mean \pm standard error ( $\mathrm{n}=6$ ) ${ }^{*} \mathrm{P}<0.05 \mathrm{vs.} \mathrm{I/R}$ group; ${ }^{\text {"}} \mathrm{P}<0.05$ vs. I/R+D group. I/R, ischemic/reperfusion; I/R+D, I/R with dimethyl sulfoxide; I/R+H, I/R with herkinorin; MCAO, middle cerebral artery occlusion.

A $1 \mathrm{~h} \mathrm{MCAO} / 24 \mathrm{~h}$ reperfusion)

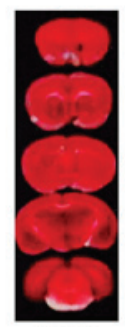

Naive
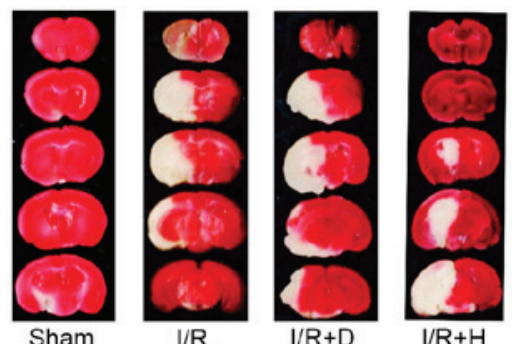

C

(1 h MCAO /7 d reperfusion)

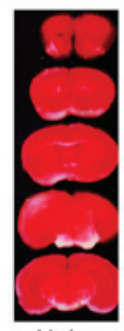

Naive

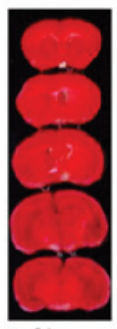

Sham

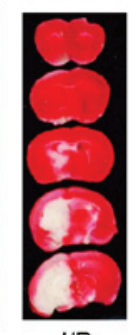

I/R

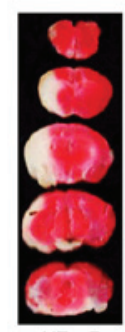

I/R+D

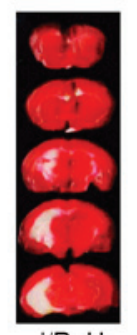

I/R+H
B

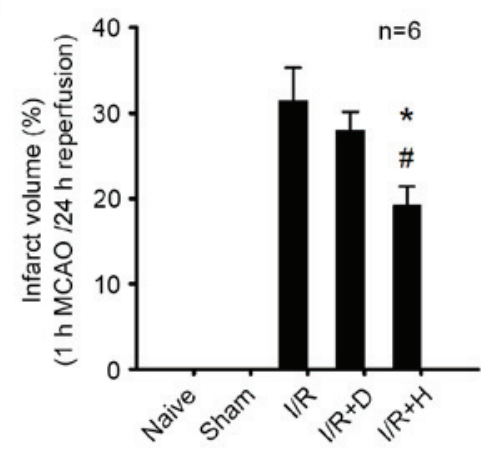

D

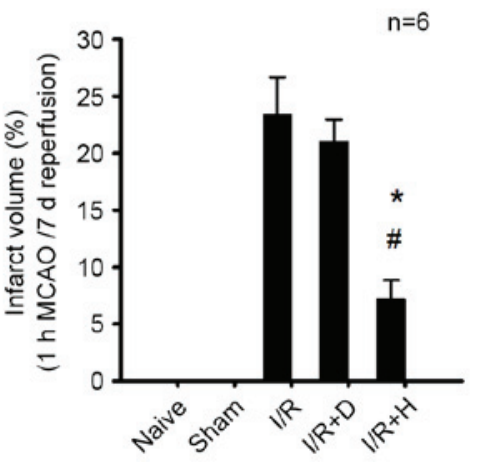

Figure 2. Effect of herkinorin on infarct volume of mice following I/R. (A) Images of TTC-stained brain coronal sections at $24 \mathrm{~h}$ after reperfusion from naïve, sham, I/R, I/R+D and I/R+H groups, and (B) quantitative analysis of infarct volume in all groups at this time point. (C) Images and (D) quantification of brain infarction 7 days after reperfusion. Red and white indicates non-infarcted and infarcted brain tissue, respectively. Brain infarct size significantly increased in the I/R and I/R+D groups at $24 \mathrm{~h}$ and 7 days after reperfusion, compared with the sham and naïve groups. Herkinorin treatment reduced $\mathrm{I} / \mathrm{R}$-induced infarction. Data are expressed as the mean \pm standard error $(\mathrm{n}=6){ }^{*} \mathrm{P}<0.05$ vs. I/R group, ${ }^{\text {}} \mathrm{P}<0.05$ vs. I/R+D group. I/R, ischemic/reperfusion; I/R+D, I/R with dimethyl sulfoxide; I/R+H, I/R with herkinorin; MCAO, middle cerebral artery occlusion; TTC, 2,3,5-triphenyltetrazolium chloride. 
the red and white areas indicating non-infarcted and infarcted brain tissue, respectively. Brain infarct size significantly increased in the I/R and I/R+D groups at $24 \mathrm{~h}$ (Fig. 2A and B) and 7 days (Fig. 2C and D) after reperfusion, compared with the sham and naïve groups $(\mathrm{P}<0.001 \mathrm{I} / \mathrm{R}$ and $\mathrm{I} / \mathrm{R}+\mathrm{D}$ group vs. naïve and sham groups at $24 \mathrm{~h}$ and 7 days). Herkinorin treatment reduced $\mathrm{I} / \mathrm{R}$-induced cerebral infarction $(\mathrm{P}=0.006$ and $0.009, \mathrm{I} / \mathrm{R}$ and $\mathrm{I} / \mathrm{R}+\mathrm{D}$ group $\mathrm{vs} . \mathrm{I} / \mathrm{R}+\mathrm{H}$ group at $24 \mathrm{~h}$; $\mathrm{P}=0.010$ and $0.011, \mathrm{I} / \mathrm{R}$ and $\mathrm{I} / \mathrm{R}+\mathrm{D}$ group vs. $\mathrm{I} / \mathrm{R}+\mathrm{H}$ group at 7 days).

Herkinorin stabilizes cPKC $\gamma$ membrane translocation level in the peri-infarct region of $I / R$ mice. Western blotting was conducted to assess the role of $c \mathrm{PKC} \gamma$ activation in herkinorin-induced neuroprotection (Fig. 3A). $\mathrm{cPKC} \gamma$ membrane translocation in the ischemic core and peri-infarct region of the ischemic cortex demonstrated a significant decrease at $24 \mathrm{~h}$ following I/R $(\mathrm{P}<0.001 \mathrm{Ic}$ and $\mathrm{P}$ of $\mathrm{I} / \mathrm{R}$ and $\mathrm{I} / \mathrm{R}+\mathrm{D}$ group vs. naïve and sham groups), and the decrease of $\mathrm{cPKC} \gamma$ membrane translocation in the peri-infarct region was attenuated by herkinorin pretreatment (Fig. 3B, $\mathrm{P}=0.006$ and $0.007, \mathrm{P}$ of $\mathrm{I} / \mathrm{R}$ and $\mathrm{I} / \mathrm{R}+\mathrm{D}$ group vs. $\mathrm{I} / \mathrm{R}+\mathrm{H}$ group). The results suggested that herkinorin may protect the mouse brain against ischemic injury via a stabilization of the $\mathrm{cPKC} \gamma$ membrane translocation level in the peri-infarct region of $\mathrm{I} / \mathrm{R}$ mice.

\section{Discussion}

In addition to pain modulation, opioids are involved in various central processes including motivation, stress, anxiety, learning and feeding. Opioids mediate neuroprotection via a variety of mechanisms. Previous studies have reported the neuroprotective effects of opioids using in vivo mouse and rat models, brain slices and cultured neurons $(5,6)$. However, side effects of opioids, including constipation and respiratory depression limit their use in the clinical setting. Herkinorin, as a first selective atypical opioid $\mu$ agonist derived from the naturally occurring plant product SA, partially addresses these problems. An important advantage of this compound is that it does not promote the recruitment of $\beta$-arrestin- 2 to the MOP receptor and does not lead to receptor internalization. As $\beta$-arrestin-2 is important for the development of morphine-induced tolerance, constipation and respiratory depression, herkinorin may be a promising therapeutic agent for the treatment of stroke with fewer adverse effects. Certain studies have investigated the antinociceptive properties and cerebral vasodilative effects of herkinorin; however, efforts have seldom been made to evaluate the neuroprotective action of this compound $(22,23)$. The present study demonstrated that administration of herkinorin into I/R mice significantly reduced infarct volume and markedly improved the recovery of neurological function.

A number of underlying mechanisms have been proposed to explain how opioid receptor agonists achieve their neuroprotective effects, the most prominent of which is the activation and translocation of PKC. PKC is regarded as an important intermediate in signal transduction and is involved in the regulation of numerous cellular functions (24). The PKC signaling pathway has been implicated as a key mediator in the protection
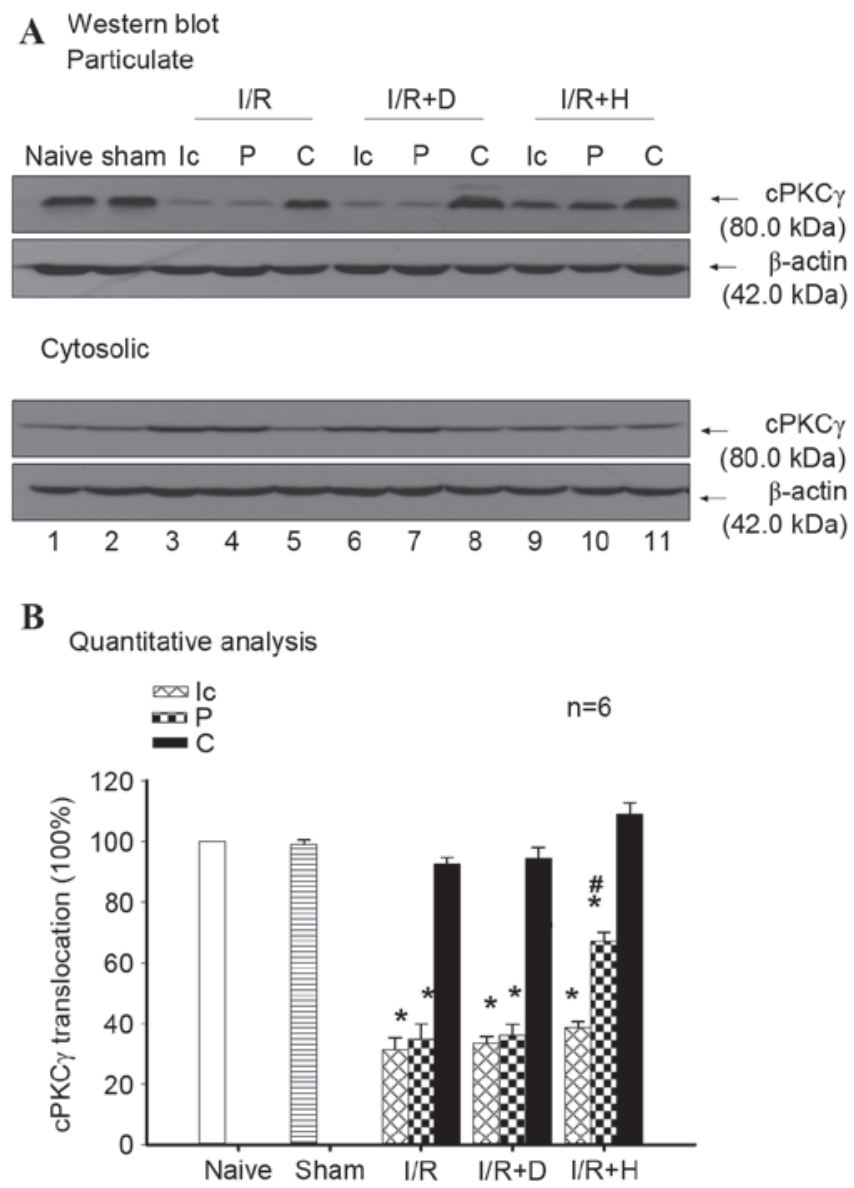

Figure 3. Herkinorin alleviates I/R-induced inhibition of $\mathrm{cPKC} \gamma$ membrane translocation in the ischemic cortex of mice. (A) Representative results of western blotting demonstrated the changes in $\mathrm{CPC} \gamma$ membrane translocation in cortex from whole brain of naïve and sham groups, and the Ic, $\mathrm{P}$ and $\mathrm{C}$ of $\mathrm{I} / \mathrm{R}, \mathrm{I} / \mathrm{R}+\mathrm{D}$ and $\mathrm{I} / \mathrm{R}+\mathrm{H}$ groups. (B) Quantitative analysis revealed that $\mathrm{cPKC} \gamma$ membrane translocation levels decreased significantly in the Ic and $\mathrm{P}$ regions of ischemic cortex; however, herkinorin pretreatment attenuated the $\mathrm{I} / \mathrm{R}$-induced inhibition of $\mathrm{cPKC} \gamma$ membrane translocation in the $\mathrm{P}$ region of MCAO mice. White and horizontally striped bars represent whole brain samples. Data are expressed as the mean \pm standard error $(n=6)$. ${ }^{*} \mathrm{P}<0.05$ vs. sham. ${ }^{~} \mathrm{P}<0.05$ vs. $\mathrm{P}$ of $\mathrm{I} / \mathrm{R}$ group. $\mathrm{I} / \mathrm{R}$, ischemic/reperfusion; $\mathrm{I} / \mathrm{R}+\mathrm{D}, \mathrm{I} / \mathrm{R}$ with dimethyl sulfoxide; I/R+H, I/R with herkinorin; MCAO, middle cerebral artery occlusion; PKC, protein kinase $\mathrm{C}$; $\mathrm{cPKC} \gamma$, conventional protein kinase $\mathrm{C} \gamma$; Ic, ischemic core; $\mathrm{P}$, peri-infarct region; $\mathrm{C}$, contralateral cortex.

against I/R injury. Furthermore, activation of PKC was proposed to be an important neuroprotective event by various studies. Wang et al (25) suggested that the activation of endogenous PKC is important in the neuroprotective mechanism underlying electroacupuncture pretreatment following focal cerebral ischemia. Our previous study revealed that activation of $\mathrm{cPKC} \gamma$ and novel PKC $\varepsilon$ may be involved in the development of cerebral hypoxic preconditioning of mice (21). The majority of studies proposed pathways of ischemic protection suggesting that endogenous or exogenous stimuli activated phospholipase $\mathrm{C}$ via $\mathrm{G}$-protein, and diacylglycerol released from phospholipid moieties activated PKC by translocating it from the cytosol to the membrane.

cPKC $\gamma$ belongs to the classical subgroup of the PKC family, and is present only in neurons of the brain and spinal cord (26). Therefore, cPKC $\gamma$ as a central nervous system-specific compound has attracted the attention of 
biochemists and neuroscientists investigating modulation of ischemic injury. Zhang et al (12) suggested that following hypoxic preconditioning, there is an increased translocation of $\mathrm{cPKC} \gamma$ in the surviving penumbra of MCAO mice. Hayashi et al (27) suggested that estrogen may induce translocation of $\mathrm{cPKC} \gamma$, and exogenous estrogen-induced neuroprotection was attenuated in $\mathrm{cPKC} \gamma$-knockout mice. These studies aimed to explain the role of $\mathrm{cPKC} \gamma$ in neuroprotection via its translocation from the cytosol to the membrane fraction upon activation. Certain studies have indicated that translocation of $\mathrm{cPKC} \gamma$ may be initiated by different types of opioid agonist. Ping et al (28) revealed a significant translocation of $\mathrm{cPKC} \gamma$ from the cytosol to the membrane component of morphine-conditioned rats in a dose-dependent manner. In addition, repeated intrathecal injection of a selective $\mu$-receptor agonist, [D-Ala ${ }^{2}$, $\mathrm{N}-\mathrm{Me}-\mathrm{Phe}^{4}, \mathrm{Gly}^{5}$-ol]-enkephalin, in the spinal cord of mice results in a translocation of $\mathrm{cPKC} \gamma$ from the cytosol to the membrane (29). The present study revealed that in the group pretreated with herkinorin, the decrease of $\mathrm{cPKC} \gamma$ membrane translocation in the peri-infarct region induced by I/R injury was attenuated.

There are numerous molecules and signaling pathways involved in the neuroprotective effects of herkinorin, and membrane translocation of $\mathrm{cPKC} \gamma$ only provides a partial explanation of this phenomenon. The investigation of only the membrane translocation of $\mathrm{cPKC} \gamma$ is a limitation of the present study. The results of the present study suggested that herkinorin exerts neuroprotective effects; a comparison between this atypical opioid agonist and clinically used morphine-like compounds is required and will be performed in future studies.

In conclusion, the results of the present study demonstrated that herkinorin may protect against I/R-induced brain injury in mice and this may potentially be attributed to the membrane translocation of cPKC $\gamma$ upon activation. These results provide a novel view of the effects and underlying mechanisms of atypical opioids in neuroprotection, and may indicate a potential novel therapeutic agent for the treatment of stroke.

\section{Acknowledgements}

The present study was supported by the National Natural Science Foundation of China (grant no. 81301065 to X.C.) and the Talent Training Plan of Beijing (grant no. D003034000031).

\section{References}

1. Schultz JE, Hsu AK and Gross GJ: Morphine mimics the cardioprotective effect of ischemic preconditioning via a glibenclamide-sensitive mechanism in the rat heart. Circ Res 78: 1100-1104, 1996.

2. Kato R and Foëx P: Fentanyl reduces infarction but not stunning via delta-opioid receptors and protein kinase $\mathrm{C}$ in rats. $\mathrm{Br} \mathrm{J}$ Anaesth 84: 608-614, 2000.

3. Saccani F, Anselmi L, Jaramillo I, Bertoni S, Barocelli E and Sternini C: Protective role of u opioid receptor activation in intestinal inflammation induced by mesenteric ischemia/reperfusion in mice. J Neurosci Res 90: 2146-2153, 2012.

4. Park SW, Yi JW, Kim YM, Kang JM, Kim DO, Shin MS, Kim CJ, Lee DI, Kim DH and Lee BJ: Remifentanil alleviates transient cerebral ischemia-induced memory impairment through suppression of apoptotic neuronal cell death in gerbils. Korean J Anesthesiol 61: 63-68, 2011.
5. Fanjun M, Junfa L, Bingxi Z and Fang J: nPKCepsilon and NMDA receptors participate in neuroprotection induced by morphine pretreatment. J Neurosurg Anesthesiol 18: 119-124, 2006.

6. Liu Y, Li J, Yang J, Ji F, Bu X, Zhang N and Zhang B: Inhibition of PKCgamma membrane translocation mediated morphine preconditioning-induced neuroprotection against oxygen-glucose deprivation in the hippocampus slices of mice. Neurosci Lett 444: 87-91, 2008.

7. Groer CE, Tidgewell K, Moyer RA, Harding WW, Rothman RB, Prisinzano TE and Bohn LM: An opioid agonist that does not induce mu-opioid receptor-arrestin interactions or receptor internalization. Mol Pharmacol 71: 549-557, 2007.

8. Raehal KM, Walker JK and Bohn LM: Morphine side effects in beta-arrestin 2 knockout mice. J Pharmacol Exp Ther 314: 1195-1201, 2005.

9. Kang M, Maguma HT, Smith TH, Ross GR, Dewey WL and Akbarali HI: The role of $\beta$-arrestin 2 in the mechanism of morphine tolerance in the mouse and guinea pig gastrointestinal tract. J Pharmacol Exp Ther 340: 567-576, 2012.

10. Chen C, Cui X, Matsunaga F, Ma J, Ma N, Abel T and Liu R: Salvinorin A decreases mortality and improves neurological outcome in a neonatal mouse hypoxia model. Transl Perioper Pain Med 1: 9-13, 2014.

11. Ding J, Ding N, Wang N, Lu Q, Lu N, Yang D, Bu X, Han S and $\mathrm{Li}$ J: Determination of conventional protein kinase $\mathrm{C}$ isoforms involved in high intraocular pressure-induced retinal ischemic preconditioning of rats. Vision Res 49: 315-321, 2009.

12. Zhang N, Yin Y, Han S, Jiang J, Yang W, Bu X and Li J: Hypoxic preconditioning induced neuroprotection against cerebral ischemic injuries and its cPKC $\gamma$-mediated molecular mechanism. Neurochem Int 58: 684-692, 2011.

13. Bu X, Zhang N, Yang X, Liu Y, Du J, Liang J, Xu Q and Li J: Proteomic analysis of cPKC $\beta$ II-interacting proteins involved in HPC-induced neuroprotection against cerebral ischemia of mice. J Neurochem 117: 346-356, 2011.

14. Rodriguez R, Santiago-Mejia J, Gomez C and San-Juan ER: A simplified procedure for the quantitative measurement of neurological deficits after forebrain ischemia in mice. J Neurosci Methods 147: 22-28, 2005.

15. Matsuura K, Kabuto H, Makino H and Ogawa N: Pole test is a useful method for evaluating the mouse movement disorder caused by striatal dopamine depletion. J Neurosci Methods 73: 45-48, 1997.

16. Karl T, Pabst R and von Hörsten S: Behavioral phenotyping of mice in pharmacological and toxicological research. Exp Toxicol Pathol 55: 69-83, 2003.

17. Li X, Blizzard KK, Zeng Z, DeVries AC, Hurn PD and McCullough LD: Chronic behavioral testing after focal ischemia in the mouse: Functional recovery and the effects of gender. Exp Neurol 187: 94-104, 2004

18. Chen J,Zhang C, Jiang H, Li Y, Zhang L, Robin A, Katakowski M, Lu M and Chopp M: Atorvastatin induction of VEGF and BDNF promotes brain plasticity after stroke in mice. J Cereb Blood Flow Metab 25: 281-290, 2005.

19. Wexler EJ, Peters EE, Gonzales A, Gonzales ML, Slee AM and Kerr JS: An objective procedure for ischemic area evaluation of the stroke intraluminal thread model in the mouse and rat. J Neurosci Methods 113: 51-58, 2002.

20. Ashwal S, Tone B, Tian HR, Cole DJ and Pearce WJ: Core and penumbral nitric oxide synthase activity during cerebral ischemia and reperfusion. Stroke 29: 1037-1047, 1998.

21. Li J, Niu C, Han S, Zu P, Li H, Xu Q and Fang L: Identification of protein kinase $\mathrm{C}$ isoforms involved in cerebral hypoxic preconditioning of mice. Brain Res 1060: 62-72, 2005.

22. Lamb K, Tidgewell K, Simpson DS, Bohn LM and Prisinzano TE: Antinociceptive effects of herkinorin, a MOP receptor agonist derived from salvinorin $\mathrm{A}$ in the formalin test in rats: New concepts in mu opioid receptor pharmacology: From a symposium on new concepts in mu-opioid pharmacology. Drug Alcohol Depend 121: 181-188, 2012.

23. Ji F, Wang Z, Ma N, Riley J, Armstead WM and Liu R: Herkinorin dilates cerebral vessels via kappa opioid receptor and cyclic adenosine monophosphate (cAMP) in a piglet model. Brain Res 1490: 95-100, 2013.

24. Nishizuka Y: Protein kinase $C$ and lipid signaling for sustained cellular responses. The FASEB Journal 9: 484-496, 1995.

25. Wang ZK, Zhang LC, Zhao SH, Zhang JW, Shang LH, Zhang YL, Lin CR and Guo JK: Effect of electroacupuncture on cerebral PKC isozyme expression levels in cerebral ischemia-reperfusion rats. Zhen Ci Yan Jiu 37: 312-317, 2012 (In Chinese). 
26. Saito $\mathrm{N}$ and Shirai Y: Protein kinase $\mathrm{C}$ gamma (PKC gamma): Function of neuron specific isotype. J Biochem 132: 683-687, 2002.

27. Hayashi S, Ueyama T, Kajimoto T, Yagi K, Kohmura E and Saito N: Involvement of gamma protein kinase $\mathrm{C}$ in estrogen-induced neuroprotection against focal brain ischemia through G protein-coupled estrogen receptor. J Neurochem 93: 883-891, 2005 .
28. Ping X, Ma Y, Li Y, Qi C, Sun X, Lv X and Cui C: Essential role of protein kinase $\mathrm{C}$ in morphine-induced rewarding memory. Neuropharmacology 62: 959-966, 2012.

29. Narita M, Mizoguchi H, Narita M, Nagase H, Suzuki T and Tseng LF: Involvement of spinal protein kinase Cgamma in the attenuation of opioid mu-receptor-mediated G-protein activation after chronic intrathecal administration of [D-Ala2, N-MePhe4, Gly-Ol(5)]enkephalin. J Neurosci 21: 3715-3720, 2001. 